\title{
Reconsidering the Mathematics Preparation of Pre-service Secondary Mathematics Teachers
}

\section{Mary Beisiegel, Josh Chesler, Dana Cox, Rachael Kenney, Jill Newton, and Jamalee Stone}

Secondary mathematics teacher preparation programs typically require pre-service teachers to complete an undergraduate degree in mathematics, or the equivalent [1,3], along with education coursework and some type of field experience. There has been substantial discussion in the mathematics education community about the mathematics coursework required of pre-service secondary mathematics teachers. Many have questioned the value of traditional undergraduate mathematics programs for future high school

Mary Beisiegel is professor of mathematics at Oregon State University. Her email address is bei siegm@onid. orst. edu.

Josh Chesler is in the Department of Mathematics and Statistics at California State University Long Beach. His email address is josh.ches 1er@su1b.edu.

Dana Cox is in the Department of Mathematics at Miami University. Her email address is Dana.Cox@MiamiOH. edu.

Rachael Kenney is in the Department of Mathematics at Purdue University. Her email address is rhkenney@ purdue.edu.

Jill Newton is in Curriculum and Instruction-College of Education-at Purdue University. Her email address is janewton@purdue.edu.

Jamalee Stone is in the Education Department at Black Hills State University. Her email address is jamistone@ bhsu. edu. mathematics teachers. Hodgson [5] noted that, within such programs, pre-service secondary mathematics teachers "have no explicit occasion for making connections with the mathematical topics for which they will be responsible in school, nor of looking at those topics from an advanced point of view" (p. 509). He endorsed the inclusion of undergraduate coursework that would help preservice teachers develop "deep conceptual understanding of the school mathematics content" (p. 512).

In 2001 the Conference Board of the Mathematical Sciences (CBMS) [3] recommended that pre-service secondary mathematics teachers complete "a 6-hour capstone course connecting their college mathematics courses with high school mathematics" (p. 8). Recently, the CBMS has released an updated version of these recommendations [4] and, rather than suggesting a specific capstone course, now proposes that pre-service secondary mathematics teachers complete the equivalent of a mathematics major "that includes three courses with a primary focus on high school mathematics from an advanced viewpoint" (p. 18). The call for pre-service secondary mathematics

Members of the Editorial Board for Doceamus are: David Bressoud, Roger Howe, Karen King, William McCallum, and Mark Saul.

DOI: http://dx.doi.org/10.1090/noti1034 
teachers to interact with high school mathematics content at a deeper level is particularly salient in light of Monk's [6] influential large-scale, longitudinal study of the effects of teachers' mathematics subject matter preparation on their students' performances. Monk declared that "having a mathematics major has no apparent effect on student performance" and suggested that training which is not directly relevant to secondary school content "cannot be counted on to have positive collateral effects" (p. 132). There is a continual call for pre-service secondary mathematics teachers to interact with high school mathematics content at a deeper level

Against this backdrop of recommendations and concerns about secondary mathematics teacher preparation, we conducted a survey [2] of universities to investigate the prevalence and nature of capstone courses one decade after the CBMS recommendations. We found that just over one third of survey respondents reported having a capstone course that aligned with the CBMS by linking high school and university mathematics content. Further, only 27 percent of these CBMS-aligned capstones (9.6 percent of all respondents) comprised at least six credit hours, as recommended.

Though the generalizability of our survey is limited by a convenience sample of 73 institutions, it is apparent that relatively few programs have a capstone course that aligns with the 2001 CBMS recommendations. Moreover, only 23 percent of these courses were intended exclusively for students seeking licensure. This seemingly limited impact of the CBMS recommendations for capstone courses is amplified by the fact that, even among institutions that have such courses, less than one third of respondents described the 2001 CBMS document as being influential in the design of the capstone course.

The CBMS-aligned capstones investigated through our study are very diverse in terms of mathematical content, course materials, and methods of assessment. A large majority of instructors for these courses indicated that they have a great deal of freedom and very few departmental (or other) guidelines for teaching this course. In terms of instructor control, course descriptions indicated that the capstones ran the gamut from independent study opportunities to lecture-driven mathematics courses. In terms of content, there was also great variability in terms of how content was selected. In some courses, it was specified entirely by the instructor and in others, negotiated between instructor and student. The instructors' backgrounds were in either mathematics (50 percent), mathematics education (15 percent), or both (35 percent).

Our survey shows that a decade after the CBMS recommendation for capstone courses, there are very few actual implementations of the recommendations. Moreover, the variety of capstone courses we found through the study is perhaps a reflection of the capstone being tailored to fit the needs of individual departments. In particular, if a capstone course is offered by the mathematics department, it is most likely designed to fit the general needs of a mathematics major and addresses advanced mathematical topics in lieu of making connections to high school mathematics. Despite recommendations, pre-service secondary mathematics teachers still have few occasions for thinking deeply about high school-level content. The current required coursework appears to be the same formal mathematics that Monk said did nothing to improve student performance [6] and does not help pre-service teachers to benefit from a deep examination of the content they will someday teach.

It is an important time to be considering recommendations put forth by national organizations. In addition to the CBMS [3] renewing and increasing the suggested focus on high school mathematics content for pre-service secondary mathematics teachers to focus on, that very content is changing on a national basis. Any programmatic changes that are responsive to $\mathrm{K}-12$ content need to be made in light of the adoption of the Common Core State Standards for Mathematics (CCSSM). Meeting these recommendations could place additional pressure on departments to develop separate sections of established courses for pre-service teachers or to offer an alternative program of study for this population in order to better prepare teachers for teaching the new content included in CCSSM.

Our study indicates that it is unlikely that the new CBMS recommendations will inspire widespread departmental change on their own. However, against the backdrop of major changes in $\mathrm{K}-12$ mathematics education, it is an opportune time for departments to uncover and question the assumptions which underlie their teacher preparation programs and to identify potential opportunities for improvement. As a community, we must put to work the practices that we know are needed to help the future students of these pre-service teachers. In particular, we and others (for example, [3] and [4]) believe that pre-service secondary mathematics teachers benefit from a deep examination of high school content. By no means do we wish to insinuate that there is no value for future teachers to take traditional upper division mathematics courses, but future teachers also stand to benefit from an equally rigorous examination of high school mathematics and statistics. Shulman [7] reminds us of our role in teaching mathematics to pre-service teachers:

Whether we call ourselves professors of education or professors of mathematics, to the extent that in our classrooms day after day sit men and women 


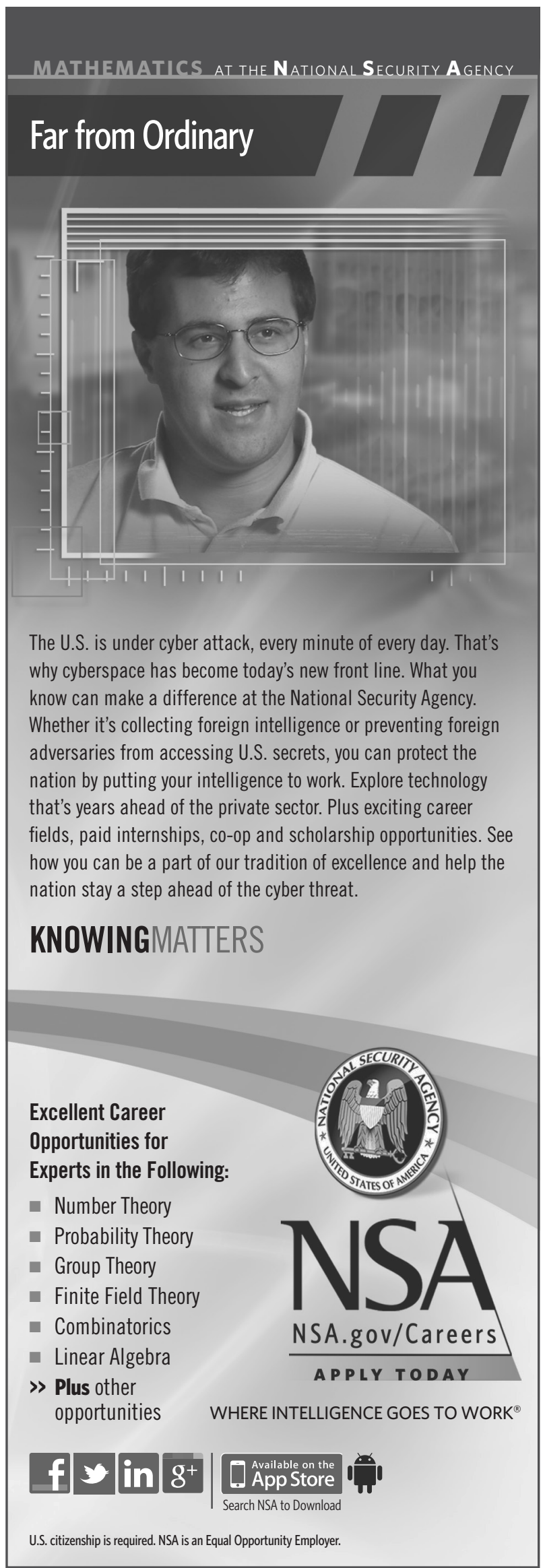

who subsequently go out and teach youngsters, we are teacher educators. To the extent that they are likely to teach both what and as they have been taught, unlike any other students in your classes, the future teachers are, if you will, carriers. Whatever understandings or misunderstandings you infect them with, both about the content and regarding the pedagogy, they will carry to generations of young people whom they will subsequently teach, and who themselves will eventually appear at your doorstep. (p. 406; emphasis in original)

Mathematics and statistics departments have the responsibility to ensure that future mathematics teachers have deep and connected understandings of the mathematics they will teach.

\section{References}

[1] A. Artzt, A. Sultan, F. R. Curcio, and T. Gurl, A capstone mathematics course for prospective secondary mathematics teachers, Journal of Mathematics Teacher Education, Online First, June 14, 2011.

[2] MARY BEISIEGEL, The status of capstone courses in the preparation of secondary mathematics teachers. In S. Brown, S. Larsen, K. Marrongelle, and M. Oehrtman (eds.), Proceedings of the 15th Annual Conference on Research in Undergraduate Mathematics Education (pp. 108-122), Portland, Oregon, 2012.

[3] Conference Board of the Mathematical Sciences (CBMS), The Mathematical Education of Teachers, American Mathematical Society, Providence, RI, 2001.

[4] Conference Board of the Mathematical Sciences (CBMS), The Mathematical Education of Teachers II, American Mathematical Society, Providence, RI, 2012.

[5] B. Hodgson, The mathematical education of school teachers: Role and responsibilities of university mathematicians. In D. A. Holton (ed.) The Teaching and Learning of Mathematics at the University Level: An ICMI Study (pp. 501-518), Kluwer Academic Publishers, Boston, Massachusetts, 2001.

[6] D. H. Monk, Subject area preparation of secondary mathematics and science teachers and student achievement, Economics of Education Review 13(2) (1994), 125-145.

[7] L. S. Shulman, The Wisdom of Practice: Essays on Teaching, Learning, and Learning to Teach, JosseyBass, San Francisco, California, 2004. 